\title{
A Hybrid Climate Model for Rainfall Forecasting based on Combination of Self- Organizing Map and Analog Method
}

(Model Iklim Hibrid untuk Ramalan Curahan Hujan berdasarkan Gabungan Peta Swaurus dan Kaedah Analog)

\author{
NATITA WANGSOH, WibOONSAK WATTHAYU* \& DUSADEE SUKAWAT
}

\begin{abstract}
A hybrid climate model (HCM) is a novel proposed model based on the combination of self-organizing map (SOM) and analog method (AM). The main purpose was to improve the accuracy in rainfall forecasting using HCM. In combination process of HCM, SOM algorithm classifies high dimensional input data to low dimensional of several disjointed clusters in which similar input is grouped. AM searches the future day that has similar property with the day in the past. Consequently, the analog day is mapped to each cluster of SOM to investigate rainfall. In this study, the input data, geopotential height at $850 \mathrm{hPa}$ from the Climate Forecast System Reanalysis (CFSR) are training set data and also the complete rainfall data at 30-meteorological stations from Thai meteorological department (TMD) are observed. To improve capability of rainfall forecasting, three different measures were evaluated. The experimental results showed that the performance of HCM is better than the traditional AM. It is illustrated that the HCM can forecast rainfall proficiently.
\end{abstract}

Keywords: Analog method; hybrid climate model; rainfall forecasting; self-organizing map

ABSTRAK

Model iklim hibrid (HCM) adalah model cadangan novel berdasarkan peta swaurus (SOM) dan kaedah analog (AM). Tujuan utama kajian ialah untuk meningkatkan ketepatan dalam peramalan curahan hujan menggunakan HCM. Dalam proses gabungan HCM, algoritma SOM mengelaskan data input dimensi yang tinggi kepada dimensi rendah daripada beberapa kelompok terputus dengan input yang sama dikumpulkan. AM mencari hari akan datang yang mempunyai sifat yang sama dengan hari pada masa lalu. Oleh yang demikian, hari analog dipetakan kepada setiap kluster SOM untuk mengkaji curahan hujan. Dalam kajian ini, input data, ketinggian geopotensi pada 850 hPa daripada Sistem Iklim Ramalan Analisis Semula (CFSR) adalah data set latihan dan juga data lengkap curahan hujan di 30 stesen meteorologi daripada Jabatan Meteorologi Thailand (TMD) adalah curahan hujan yang dicerap. Untuk memperbaiki keupayaan ramalan curahan hujan, tiga langkah berbeza telah dinilai. Keputusan uji kaji menunjukkan prestasi HCM adalah lebih baik daripada AM tradisi. Ditunjukkan bahawa HCM boleh meramalkan hujan dengan cekap.

Kata kunci: Kaedah analog; model hibrid iklim hujan ramalan; peta swaurus

\section{INTRODUCTION}

The rainfall information is an essential requirement for planning in sustainable management of water resources. The rainfall causes flood or drought. It also has influence on agriculture land, transportation, industry and others human activities. Furthermore, rainfall is one of the most complex elements in hydrologic cycle to be forecasted and very difficult to be measured due to the wide variation range of scales both in space and time (Mark et al. 1992). Thus, the ability of rainfall forecasting is very beneficial to anticipate the impact and to design the protection plan. One possible technique to produce the accurate potential of forecasting results in hydrologic processes is statistical downscaling methods. It is based on the concept of transferring large-scale atmospheric variables that are called predictors, to local-scale weather series, predictands (Jiaming et al. 2015). Main advantages of statistical downscaling are inexpensive to computation and ability for the local information. In the past, many techniques on statistical downscaling, weather classification, regression method and weather generators, had been widely applied. Neural network (NN) is common use and inspires by biological nervous system. It is a mathematical model for solving nonlinear problems. Furthermore, it can learn and classify characteristics of the training data set. The application of $\mathrm{NN}$ in hydrology could be evaluated in model of rainfall runoff, stream flow, water quality and ground water (Rakesh \& Tanweer 2015). There are two major learning algorithms in NN: supervised and unsupervised learning. Self-organizing map (SOM) is one of unsupervised learning algorithms in $\mathrm{NN}$ that has strong potential in visualizing the group of data.

SOM is first used in speech recognition which is introduced by Teuvo in 1990 as a special class of NN. It can reduce high-dimensional datasets into a low dimensional for exploring linear and nonlinear relations. As mentioned 
previously, a group of similar characteristic data can be classified. SOM is nowadays regarded as a general dataanalysis method in a number of fields and also has been successfully applied in the fields of clustering, pattern recognition, data compression and data mining. Moreover, it is currently utilized in hydrology. Various studies in hydrologic applications use SOM to develop the forecast accuracy such as typhoon rainfall (Lin \& Wu 2009), river flow (Ismail et al. 2012) and precipitation (Diego et al. 2011).

In general, one of several techniques in statistical downscaling is analog method (AM). It is applied for weather predictability assessments and short-term forecasts (Fredrik et al. 2005). There are two basic ideas of AM. First, it establishes simultaneous relationships between predictors and predictands. Second, it finds the future predictands from the observed data in similar situation. $\mathrm{AM}$ has been generally used in weather prediction and seasonal forecasting (Christoph et al. 2008). Many reviews of previous study showed that AM is better than a statistical downscaling method. AM has comparable performance in rainfall downscaling over the Iberian Peninsula when it compares with more complicated techniques (Eduardo \& Hans 1999). Likewise, AM has potential for seasonal rainfall forecasting in the Murray Darling Basin (Andrew et al.2013). In the results, they suggested that AM is the worse results for downscaling in different choice of predictors.

Hybrid model becomes useful tool in aspect of forecast accuracy improvement. There are several studies that demonstration of the forecasting result of hybrid model is better than the traditional model. In this regard, SOM is widely applied in many hybrid models for improving the forecast accuracy, for example, Lin and Wu (2009). They combine SOM with the multilayer perceptron network (MLPN) to improve the accuracy of typhoon-rainfall forecasts over the Tanshui River Basin. Ismail et al. (2012) integrate SOM with least squares support vector machines (LSSVM) to test the capability and effectiveness of the model in river flow forecasting. Roberto et al. (2015) compound SOM with the Monte Carlo method in wind fields downscaling.

As mentioned earlier, there are some limitations of SOM and AM. SOM can classify the pattern of rainfall but it cannot forecast rainfall. However, AM is successful in searching analog day, it is unable separate the pattern of rainfall. In this study, HCM is therefore introduced to improve the accuracy of rainfall forecasting based on the combination of SOM and AM. The designed model not only classifies the rainfall pattern but also predicts rainfall.

\section{DATA AND METHODS}

\section{DATA DESCRIPTION AND STUDY AREA}

Thailand is located between latitude $5^{\circ} \mathrm{N}$ and $20^{\circ} \mathrm{N}$ and longitude $97^{\circ} \mathrm{E}$ and $105^{\circ} \mathrm{E}$. The study domain is shown as Figure 1.

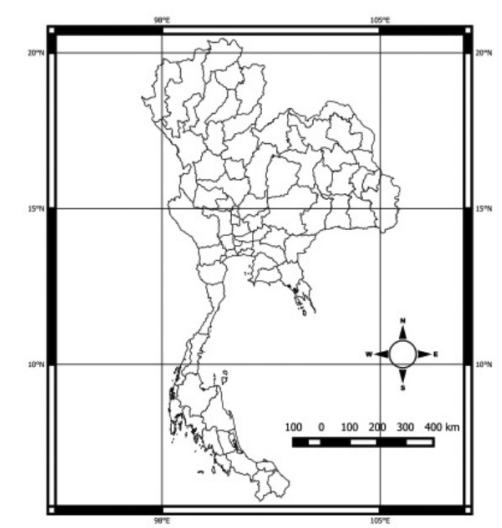

FIGURE 1. Study domain

The data in this study are divided into two parts: Geopotential height and rainfall data. The first part, input data for SOM and AM, is from the Climate Forecast System Reanalysis (CFSR). CFSR is developed in the Environmental Modelling Center at the National Centers for Environmental Prediction (NCEP). The components of CFSR, atmospheric, oceanic, land-surface and data assimilation, have been achieved at an hourly time with 37 pressure levels for the atmosphere and 40 levels for the ocean. CFSR is completed for the 32-year data from 1979 to 2010 and initialized 4 times per day, 0000, 0600, 1200 and 1800 UTC in 52 variables (Suranjana et al. 2014). In this study, only the $850 \mathrm{hPa}$ geopotential height data at 0000 UTC, the period from 15 May 1979 to 15 October 1999 are selected to train the model and the data between 2000 and 2009 are used as testing set. Table 1 shows the data description.

TABLE 1. Data description

\begin{tabular}{ll}
\hline Domain & Latitude $5^{\circ} \mathrm{N}$ to $20^{\circ} \mathrm{N}$ and longitude $97^{\circ} \mathrm{E}$ to $105^{\circ} \mathrm{E}$ \\
Predictor & The $850 \mathrm{hPa}$ geopotential height at $0000 \mathrm{UTC}$ \\
Date & 15 May to 15 October between 1979 and 2010 \\
\hline
\end{tabular}

The second part is Thailand daily historical rainfall data from Thai Meteorological Department (TMD) used to average compute and forecast rainfall data. It is chosen depending on the available data during 15 May 1979 to 15 October 2010. Hence, the collected meteorological rainfall data contains only thirty stations.

\section{SELF-ORGANIZING MAP ALGORITHM}

SOM is an unsupervised learning algorithm in NN. The architecture composes of two components: Input and output layers. SOM is a concept of competition networks that try to find the most minimum distance between the neuron of input and output layers to present in a lower dimensional structure. A neuron in input layer is connected to all neurons in output layer with weighted links. The neurons output will be self-organized by nearby weight and group either 
(Ismail et al. 2012). Let $\mathbf{x}=\left[x_{1}, x_{2}, \ldots, x_{n}\right]$ be input vector and $\mathbf{w}=\left[w_{i 1}, w_{i 2}, \ldots, w_{i m}\right]$ be weight vector where $n$ is the dimension of the input vector, $m$ is the dimension of weight vector for $i=1,2, \ldots, n$.

At the start of the learning, all the weights, w is initialized to small random numbers. Euclidian distance, $d$ is usually used to compute the distance between the input vector and weight vector. The Euclidian distance can be written as

$$
d(\mathbf{x}, \mathbf{w})=\|\mathbf{x}(t)-\mathbf{w}(t)\|=\sum_{i=1}^{n}\left(x_{i}(t)-w_{i}(t)\right)^{2}
$$

Then, SOM algorithm will search for the output neuron with weight vector which has the minimum distance as the winner neuron (Best Matching Unit, BMU). BMU is calculated as

$$
B M U=\arg \min || \mathbf{x}(t)-\mathbf{w}(t)||
$$

To increase the similarity with the input vector, weights are required to be adjusted after obtaining the winning neuron. The rule for updating the weight vector is defined as

$$
\mathbf{w}(t+1)=\mathbf{w}(t)+\alpha(t) h_{i j}^{c}(t)\left(\mathbf{x}(t)-\mathbf{w}_{i}(t)\right)
$$

where $\alpha(t)$ is a learning rate, $h_{i j}^{c}(t)$ is a neighborhood function and $t$ is the number of iterations (José et al. 2012).

\section{LEARNING PARAMETERS}

The learning rate is a decreasing function of time training parameter that controls the size of weight vector in learning of SOM. Three learning rate function, linear, inverse of time and power series are mostly used. They can be expressed as (4) to (6), respectively.

$$
\begin{aligned}
& \alpha(t)=\alpha(0) \cdot \frac{1}{t} \\
& \alpha(t, T)=\alpha(0) \cdot\left(1-\frac{t}{T}\right) \\
& \alpha(t, T)=\alpha(0) \cdot e^{\frac{t}{T}}
\end{aligned}
$$

Neighborhood function influences the training result of SOM procedure. It determines the strength of the connection between neuron and others. In the following learning rate, Bubble and Gaussian functions are expensively presented in SOM as (7) to (8), respectively.

$$
\begin{aligned}
h_{i j}^{c} & =\left\{\begin{array}{l}
\alpha(t),(i, j) \in N_{c} \\
0,(i, j) \notin N_{c}
\end{array}\right.
\end{aligned}
$$

where $\alpha$ is the learning rate; $t$ is the order number of current iterations; and $T$ is the number of iterations; $N_{c}$, $i$ and $j$ are the number of the index set, row and column of neighborhood around the nodes with indices, $c$, respectively. The radius of neighborhood, $\boldsymbol{\eta}_{i j}^{c}$, represents the neighbor rank between nodes $w_{c}$ and $w_{i j}$. Two-dimensional vectors, $R_{c}$ and $R_{i j}$, include indexes of $w_{c}$ and $w_{i j}$ (Pavel \& Olga 2011).

In order to investigate the appropriate learning parameters of the model, two measurements; quantization error and frequency analysis, are required. The percentage of occurrence or frequency of each cluster is the number of occurrences divided by the total number of samples. The probability that geopotential height map to a pattern is $1 / n$, where $n$ is the number of patterns. The significance of the frequency can be determined by calculating the $95 \%$ confidence interval around the expected probability of $1 / n$ (Allan 2009). Quantization error (QE) is a technique to measure the quality of SOM which is computed as

$$
Q E=\frac{\sum_{i=1}^{N}\left\|x_{i}-w_{i}\right\|}{N}
$$

where $N$ is the number of input data used to train the map (Pavel \& Olga 2011).

\section{ANALOG METHOD}

The analog method, AM, is a simple statistical technique used to simulate the future predictand. It is based on finding similar characteristic predictand at target time from historical predictor which is defined as analog day in this study.

Let $\mathbf{p}_{d, v}(t)$ be a predictor from CFSR and $\mathbf{q}_{d}(t)$ be a predictor in the year 2010 from the NCEP climate forecast system version 2 .

Euclidian distance is applied to measure the similarity between $\mathbf{p}_{d, y}(t)$ and $\mathbf{q}_{d}(t)$. It is given by

$$
E_{y}=\left(\sum_{d=1}^{154}\left[\mathbf{p}_{d, y}(t)-\mathbf{q}_{d}(t)\right]^{2}\right)^{1 / 2}
$$

where $t=0000 \mathrm{UTC}, d$ is the number of day from $15^{\text {th }}$ May to $15^{\text {th }}$ October and $y$ is the number of year from 1979 to 1999.

Hence, the analog day is found numerically by selecting as

$$
\min \left(E_{1979}, E_{1980}, \ldots, E_{1999}\right)
$$

Assuming the simulated predictand at $u, \hat{S}(u)$ is equal to the predictand at $y, S(y)$. It means that the amount of rainfall is attached to a specific pattern of the $850 \mathrm{hPa}$ geopotential height. The target predictand estimation is then (Fredrik et al. 2005)

$$
\hat{S}(u)=S(y)
$$


For example, to find analog day on 15 May 2010, (10) is calculated. The result from (10) is compared to 15 May for every year, from 1979 through 2009. According to (11), the minimum Euclidian distance is as analog day of 15 May 2010. In the following Equation (12), $\hat{S}(u)$ on 15 May 2010 is equal to rainfall of analog day, $S(y)$.

\section{A HYBRID CLIMATE MODEL}

The combination of SOM and AM The proposed hybrid climate model is the combination of SOM algorithm and AM. The scheme of HCM is shown as Figure 2. There are three main processes including SOM, AM and hybrid methods. In SOM, the data from CFSR have to be normalized to reduce the discrepancy in the magnitude of the input vectors in the range of $[0,1]$ as follows:

$$
v_{\text {normalized }}=\frac{x_{i}-x_{\min }}{x_{\text {max }}-x_{\min }}
$$

where $x_{i}$ is the input data; $x_{\max }$ is the maximum value of predictor; and $x_{\min }$ is the minimum value of predictor (José et al. 2012).

Then, they are fed into SOM for training the model to separate similar characteristic into several disjointed clusters. After that, similar characteristic data are the members of cluster. The historical rainfall for each member is imported from TMD to be computed the average rainfall in the clusters. Meanwhile, the input data are searched for analog day in AM.

In hybrid process, analog day from $\mathrm{AM}$ and the member in each cluster are mapped to find the frequency in each cluster. The frequency is represented as weights. The HCM executes forecasted rainfall by the sum of multiples of average rainfall and weight. It can be written in mathematical form as,

$$
R_{k}=\sum_{i=1}^{r} \sum_{j=1}^{r} F_{i j} A_{i j}, k=1,2, \ldots, 30
$$

where $i$ is the number of row; $j$ is the number of column, $r$ is the maximum number and column, $R_{k}$ is a rainfall at meteorological station; $k, F_{i j}$ is the weight; and $A_{i j}$ is the average rainfall of a cluster.

Relative error (RE), Nash-Sutcliffe coefficient of efficiency (NSC) and coefficient correlation (CC) have been determined to evaluate the performance of HCM. RE can describe the accuracy of the model. NSC and CC can explain whether relation between observed rainfall and forecasted rainfall are close. RE, NSC and CC are defined as follows.

$$
\begin{aligned}
& \mathrm{RE}=\frac{\sum_{k=1}^{30} X_{\text {fore }}^{k}-\sum_{k=1}^{30} X_{\mathrm{obs}}^{k}}{\sum_{k=1}^{30} X_{\mathrm{obs}}^{k}} \times 100 \%, \\
& \mathrm{NSC}=1-\frac{\sum_{k=1}^{30}\left(X_{\mathrm{obs}}^{k}-X_{\mathrm{fore}}^{k}\right)^{2}}{\sum_{k=1}^{30}\left(X_{\mathrm{obs}}^{k}-\bar{X}_{\mathrm{obs}}\right)^{2}} \\
& \mathrm{CC}=\frac{\sum_{k=1}^{30}\left(X_{\mathrm{obs}}^{k}-\bar{X}_{\mathrm{obs}}\right)\left(X_{\text {fore }}^{k}-\bar{X}_{\text {fore }}\right)}{\sqrt{\sum_{k=1}^{30}\left(X_{\mathrm{obs}}^{k}-\bar{X}_{\mathrm{obs}}\right)^{2} \sum_{k=1}^{30}\left(X_{\text {fore }}^{k}-\bar{X}_{\text {fore }}\right)^{2}}}
\end{aligned}
$$

where $X_{\mathrm{obs}}^{k}$ is observed rainfall at $k, X_{\text {fore }}^{k}$ is forecast data at $k, \bar{X}_{\text {obs }}$ is mean of observed rainfall and $\bar{X}_{\text {fore }}$ is mean of forecast data. As such NSC and CC values should be close to

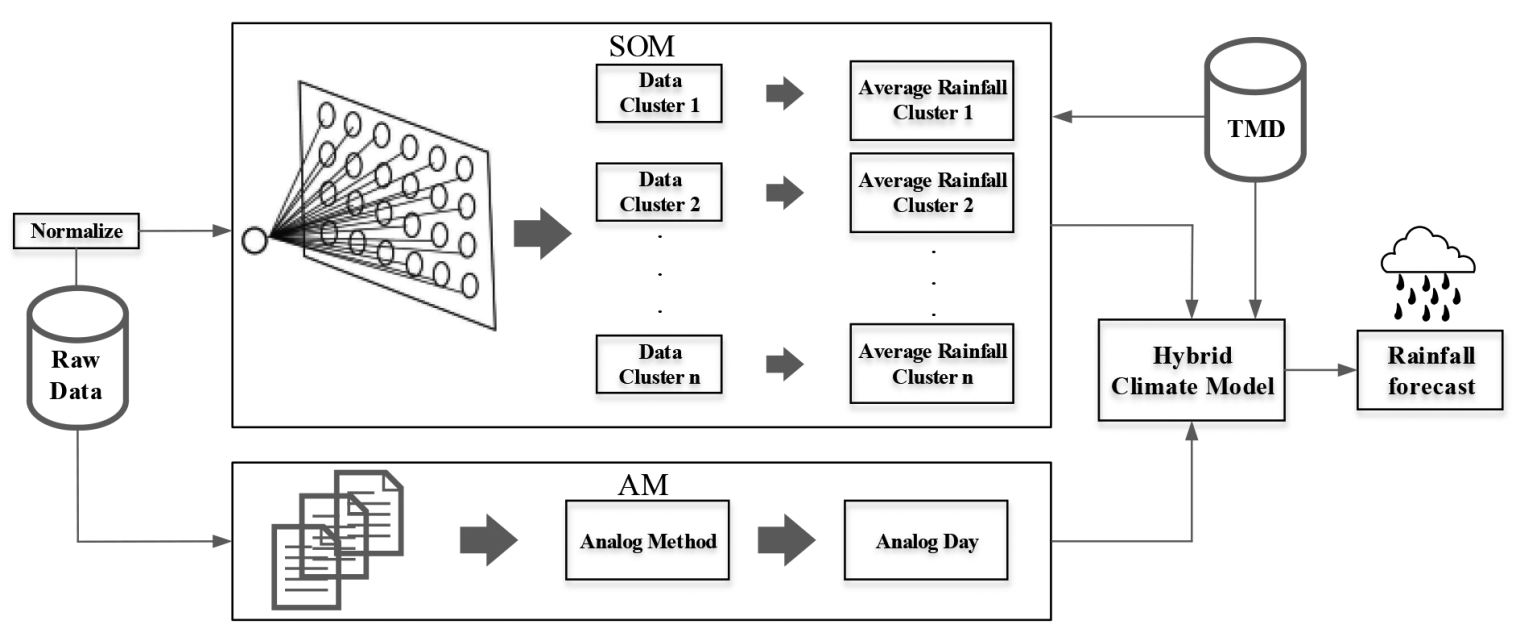

FIGURE 2. The scheme of HCM 
1. The RE value is considered satisfactory range below $10 \%$ and excellent when it less than 5\% (Jiaming et al. 2015).

\section{RESULTS AND DISCUSSION}

\section{PARAMETER SETTING}

In order to set the appropriate parameters, there are no theoretical existing criteria (Lin \& Wu 2009). The various parameters may lead to different results. In SOM algorithm, three major parameters, map size, learning rate function and neighborhood function impact the results. Thus, three initial learning rate, three learning rate functions and two neighborhood functions are investigated to find the optimal case. The dimensional aspect of map size, the suitable case can be obtained by user requirements (Ismail et al. 2012). The map size plays an important role in SOM because it affects the computational time. This study has examined four different map sizes, namely, 2 $\times 2,3 \times 3,4 \times 4$ and $5 \times 5$. In the experiment, it is found that only nine clusters are optimal dimension map size. If map size is less than $3 \times 3$, many different data map to the same pattern. Otherwise, some patterns have no member. Table 2 shows average quantization error in each experiment. According to Table 2, Gaussian function with a power series learning rate function and initial learning rate, 0.85 , is higher potential than others. Since a power series learning rate function can import all input columns into the SOM algorithm.

Table 3 shows the frequency which an analog day is mapped to a cluster of predictor. The value of rainfall forecasts have been classified into five catagories: Very dry (VD), dry (D), normal (N), wet (W) and very wet (VW) using 20th percentile as shown in Table 4. The HCM is able to predict the category of rainfall which is compared to the category of observed rainfall. In 2010, 11-meteorological stations have the same category as observed rainfall using HCM. However, only 6-meteorological stations have the same category as observed rainfall using traditional AM.

VD is less than 20th percentile, D is between 20th40th percentile, $\mathrm{N}$ is between 40 th- 60 th percentile, $\mathrm{W}$ is

TABLE 2. Average quantization error in experiments

\begin{tabular}{ccccccc}
\hline \multirow{2}{*}{$\begin{array}{c}\text { Initial } \\
\text { Learning Rate }\end{array}$} & Linear & $\begin{array}{c}\text { Inverse of } \\
\text { Time }\end{array}$ & $\begin{array}{c}\text { Power } \\
\text { Series }\end{array}$ & Linear & $\begin{array}{c}\text { Inverse of } \\
\text { Time }\end{array}$ & $\begin{array}{c}\text { Power } \\
\text { Series }\end{array}$ \\
\cline { 2 - 7 } & 0.0016 & 0.0003 & 0.0005 & 0.0004 & 0.0004 & 0.0016 \\
0.35 & 0.0002 & 0.0053 & 0.0003 & 0.0033 & 0.0019 & 0.0022 \\
0.60 & 0.0017 & 0.0003 & 0.0001 & 0.0015 & 0.0012 & 0.0015 \\
\hline
\end{tabular}

TABLE 3. Frequency of analog days in cluster

\begin{tabular}{cccc}
\hline Cluster & 1 & 2 & 3 \\
\hline 1 & 52 & 11 & 11 \\
2 & 13 & 6 & 5 \\
3 & 11 & 12 & 33 \\
\hline
\end{tabular}

TABLE 4. Seasonal rainfall conditions at 30-meteorological stations

\begin{tabular}{|c|c|c|c|c|c|c|c|c|c|}
\hline No. & Stations Name & Observed & $\mathrm{AM}$ & $\mathrm{HCM}$ & No. & Stations Name & Observed & $\mathrm{AM}$ & $\mathrm{HCM}$ \\
\hline S1 & Chiang Rai & VW & $\mathrm{N}$ & $\mathrm{W}$ & S16 & Nakhon Sawan & VW & VD & $\mathrm{W}$ \\
\hline $\mathrm{S} 2$ & Chiang Mai & VD & VD & VD & S17 & Roi Et & $\mathrm{D}$ & $\mathrm{D}$ & W \\
\hline S3 & Lam Pang & $\mathrm{N}$ & VD & $\mathrm{N}$ & S18 & Ubon Ratchatani & $\mathrm{N}$ & VD & $\mathrm{N}$ \\
\hline $\mathrm{S} 4$ & Phare & $\mathrm{W}$ & $\mathrm{D}$ & W & S19 & Suphan Buri & $\mathrm{N}$ & $\mathrm{D}$ & $\mathrm{N}$ \\
\hline S5 & Nan & VW & $\mathrm{D}$ & $\mathrm{N}$ & S20 & Lop Buri & VW & $\mathrm{D}$ & $\mathrm{N}$ \\
\hline S6 & Uttaradit & $\mathrm{W}$ & VD & W & $\mathrm{S} 21$ & Pachin Buri & VW & VW & VW \\
\hline S7 & Nong khai & $\mathrm{N}$ & VD & $\mathrm{N}$ & S22 & Surin & $\mathrm{D}$ & $\mathrm{D}$ & $\mathrm{W}$ \\
\hline S8 & Loei & VW & VD & $\mathrm{N}$ & S23 & Sa Kaeo & $\mathrm{W}$ & $\mathrm{N}$ & $\mathrm{D}$ \\
\hline S9 & Sakon Nakhon & $\mathrm{D}$ & VD & $\mathrm{N}$ & S24 & Kanchanaburi & VW & VD & $\mathrm{N}$ \\
\hline S10 & Nakhon Phanom & $\mathrm{D}$ & $\mathrm{D}$ & W & S25 & Chumphon & VD & VD & $\mathrm{N}$ \\
\hline S11 & Tak & W & VD & W & S26 & Ko Samui & $\mathrm{W}$ & VD & $\mathrm{N}$ \\
\hline S12 & Mae Sot (Tak) & $\mathrm{D}$ & VD & $\mathrm{N}$ & S27 & Nakhon Srithummarat & $\mathrm{N}$ & $\mathrm{D}$ & $\mathrm{N}$ \\
\hline S13 & Phumipol Dam & VW & VD & W & $\mathrm{S} 28$ & Phuket & $\mathrm{N}$ & $\mathrm{W}$ & $\mathrm{D}$ \\
\hline S14 & Petchabun & $\mathrm{N}$ & VD & $\mathrm{W}$ & S29 & Phuket(Center) & VW & $\mathrm{N}$ & $\mathrm{N}$ \\
\hline S15 & Khon Kaen & $\mathrm{N}$ & VD & $\mathrm{N}$ & S30 & Trang & VD & $\mathrm{W}$ & $\mathrm{D}$ \\
\hline
\end{tabular}


TABLE 5. Performance of difference methods in seasonal rainfall forecasting

\begin{tabular}{cccc}
\hline Model & NSC & CC & RE (\%) \\
\hline AM & 0.6092 & 0.7805 & 22.2314 \\
HCM & 0.6856 & 0.8515 & 3.0675 \\
\hline
\end{tabular}

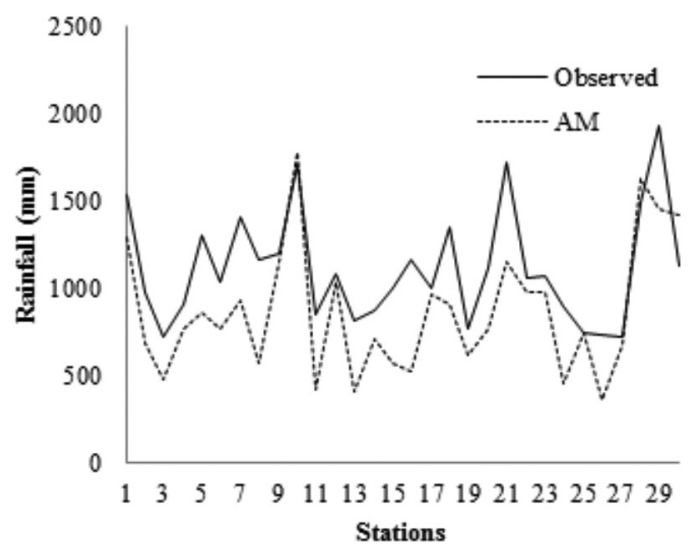

(a) Forecasted rainfall by AM

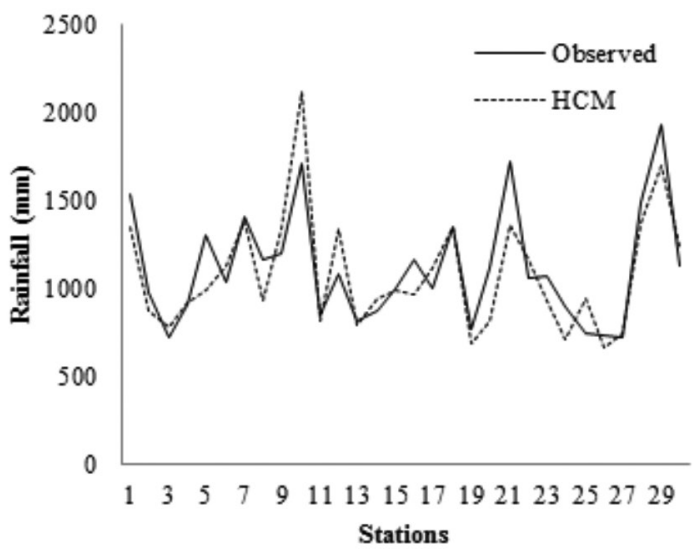

(b) Forecasted rainfall by HCM

FIGURE 3. Comparison of forecasted rainfall and observed rainfall in 2010 at 30-meteorological stations of Thailand

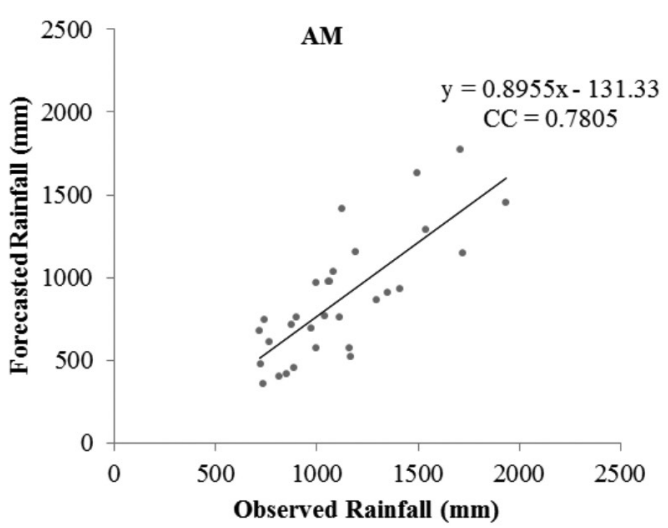

(a) $\mathrm{AM}$

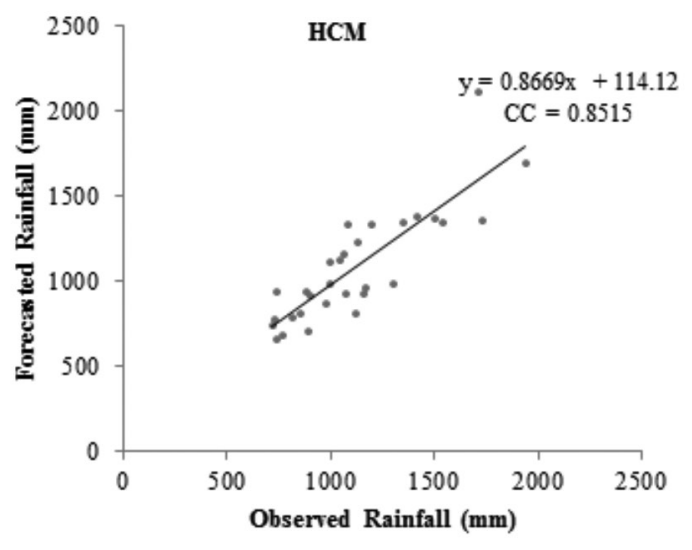

(b) $\mathrm{HCM}$

FIGURE 4. Correlation of forecasted and observed rainfall in 2010 at 30-meteorological stations of Thailand

between 60 th- 80 th percentile and VW is greater than 80 th percentile

Three different measures of NSC, CC and RE are demonstrated in Table 5. In AM, the value of RE is greater than $10 \%$ which is outside the satisfactory range. All measures of HCM are within the satisfactory accuracy range. The proposed model can reduce the traditional AM about $19.1639 \%$ in RE. In this regard, the results show that both NSC and CC values of HCM are close to 1. They are more than the traditional AM. Thus, the relationship between forecasted and observed rainfall is very strong. HCM is reasonable to apply for rainfall forecasting and to improve the accuracy skill.
Figure 3(a) shows the forecasted rainfall of the traditional AM at 30-meteorological stations compared with observed rainfall. It has wide range between the traditional AM and observed rainfall. However, in Figure 3(b), HCM seems nearly different range more than Figure 3(a) for many meteorological stations. Figures 4(a) and 4(b) illustrates the correlation of forecasted and observed rainfall at 30-meteorological stations of Thailand. In Figure 4(a), the rainfall data express widely scattered around straight line more than Figure 4(b). The rainfall data of HCM lie relatively to a straight line in Figures 4(b). It is shown that HCM has stronger linear relationship than the traditional AM. 


\section{CONCLUSION}

In this study, the hybrid climate model based on a combination of SOM and AM is introduced as the proposed model. The geopotential height at $850 \mathrm{hPa}$ is used as predictor collected by the idea of how it influences on rainfall. Gaussian function with a power series learning rate function and initial learning rate, 0.85 , are optimal parameters for HCM. The frequency that analog day is mapped to each cluster is represented as real weight. The rainfall in a cluster is determined by the average of similar characteristic for the input data. The performance of HCM measured by NSC and CC provides high efficiency. It is surprised that RE is less than $5 \%$. Thus, the proposed model can be applicable to improve rainfall forecasting skill. However, only geopotential height data are considered for the model in this study, so various predictors such as temperature, specific humidity and mean sea level pressure should be investigated in future study.

\section{ACKNOWLEDGEMENTS}

This research has been financially supported by the Human Resource Development in Science Project (Science Achievement Scholarship of Thailand, SAST) and King Mongkut's University of Technology Thonburi. The authors declare that there is no conflict of interests regarding the publication of this paper.

\section{REFERENCES}

Allan, H. 2009. A Concise Guide to Clinical Trials. Oxford: John Wiley \& Sons, Inc. pp. 205-207.

Andrew, N.C., Bertrand, T., Elodie, F. \& Harry, H. 2013. Analog downscaling of seasonal rainfall forecasts in the Murray Darling basin. Monthly Weather Review 141(3): 1099-1117.

Christoph, M., Xuebin, Z., Xiaolan, L.W., Jiafeng, W., Eduardo, Z., Sebastian, W. \& Hans, V.S. 2008. Influence of similarity measures on the performance of the analog method for downscaling daily precipitation. Climate Dynamics 30(2): 133-144.

Diego, R., Mario, L., Cintia, B.U. \& Max, B. 2011. Forecasting monthly precipitation in central Chile: a self-organizing map approach using filtered sea surface temperature. Theoretical and Applied Climatology 107(1): 1-13.

Eduardo, Z. \& Hans, V.S. 1999. The analog method as a simple statistical downscaling techniques: Comparison with more complicated methods. Journal of Climate 12: 2474-2489.

Fredrik, W., Sven, H. \& Xu, C-Y. 2005. Statistical precipitation downscaling in central Sweden with analogue method. Journal of Hydrology 306: 174-190.

Ismail, S., Shabir, A. \& Samsudin, R. 2012. A hybrid model of self-organizing maps and least square support vector machine for river flow forecasting. Hydrology and Earth System Sciences 16: 4417-4433.
Jiaming, L., Di, Y., Liping, Z., Xia, Z. \& Xingyuan, S. 2015. Comparison of three statistical downscaling methods and ensemble downscaling method based on Bayesian model averaging in upper Hanjiang river basin, China. Advances in Meteorology 2016: Article ID. 7463963.

José, A.S., Brígida, R., Arthur, A. \& José, R.S. 2012. Recurrent self-organizing map for severe weather patterns recognition. InTech.pp. 151-175.

Lin, G-F. \& Wu, M-C. 2009. A hybrid neural network model for typhoon-rainfall forecasting. Journal of Hydrology 375: 450-458.

Mark, N.F., Witold, F.K. \& Robert, R.C. 1992. Rainfall forecasting in space and time using a neural network. Journal of Hydrology 137: 1-31.

Pavel, S. \& Olga, K. 2011. Influence of learning rates and neighboring functions on self-organizing maps. Advances in Self-Organizing Maps 6731: 141-150.

Rakesh,T.\& Tanweer, S.D. 2015. Application of artificial neural network in hydrology-a review. International Journal of Engineering Research \& Technology 4(6): 184-188.

Roberto, C., Sergio, L., Javier, S. \& Oliver, P. 2015. Statisticaldynamical downscaling of wind fields using self-organizing maps. Applied Thermal Engineering 75: 1201-1209.

Suranjana, S., Shrinivas, M., Xingren, W., Jiande, W., Sudhir, N., Patrick, T., David, B., Yu-Tai, H., Hui-ya, C., Mark, I., Michael, E., Jesse, M., Rongqian, Y., Malaquías, P.M., Huug van den, D., Qin, Z., Wanqiu, W., Mingyue, C. \& Emily, B. 2014. The NCEP Climate Forecast System Version 2. Journal of Climate 27: 2185-2208.

Teuvo, K. 1990. The self-organizing map. Proceeding of the IEEE 78(9): 1464-1480.

Natita Wangsoh \& Wiboonsak Watthayu

Department of Mathematics, Faculty of Science

King Mongkut's University of Technology Thonburi (KMUTT)

126 Pracha Uthit Rd., Bang Mod, Thung Khru

Bangkok 10140

Thailand

Dusadee Sukawat

Joint Graduate School of Energy and Environment, KMUTT

126 Pracha Uthit Rd., Bang Mod, Thung Khru

Bangkok 10140

Thailand

*Corresponding author; email: iwibhayu@kmutt.ac.th

Received: 22 November 2016

Accepted: 1 April 2017 